\title{
Análise hierárquica dos problemas existentes na produção de mel do Estado da Paraíba
}

\section{Hierarchical analysis of existing problems at Honey Production the State of Paraiba}

\author{
Rubênia de Oliveira Costa ${ }^{1}$, Augusto Henrique Alves Bezerra ${ }^{2}$, Aline Costa Ferreira ${ }^{3}$, Bárbara Bruna Maniçoba Pereira ${ }^{4}$, \\ Thiago Alves Pimenta ${ }^{5}$, Anderson Bruno Anacleto de Andrade 6
}

Resumo: A produção de mel representa uma das atividades produtivas que fornece grandes oportunidades para a agricultura familiar na região nordeste, proporcionando o desenvolvimento econômico e social dos que exercem esta atividade. Porém é uma atividade que representa alguns entraves durante a produção, gerando perdas e produtos impróprios para o consumo. Baseada nisso, esta pesquisa tem o objetivo de analisar os problemas existentes na produção de mel do Estado da Paraíba com a utilização do método de análise hierárquica (AHP). Quanto aos procedimentos metodológicos, inicialmente foi feito um levantamento bibliográfico para identificar os problemas da produção de mel apontados na literatura, em seguida foram feitas entrevistas semiestruturada com especialistas que trabalham na apicultura paraibana e listados os problemas encontrados na produção de mel no estado. Esta lista foi validada pelos entrevistados. Para a hierarquização dos problemas utilizou-se o método de análise hierárquica (AHP). Os resultados da pesquisa mostram que dentre as etapas do processo produtivo a manutenção é a etapa que causa maior impacto no processo, e que os maiores problemas existentes na apicultura paraibana são a proximidade do apiário à criação de gado e cavalo, a falta do manejo das melgueiras, a falta de higiene durante o processo de beneficiamento do mel, a falta de calendário de floradas e a localização inadequada dos apiários.

Palavras-chave: Agricultura Familiar, Apicultura, AHP.

Abstract: Honey production is one of the productive activities that provide great opportunities for family farmers in the Northeast, providing economic and social development of those engaged in this activity. But it is an activity that represents some obstacles during production, generating losses and product unfit for consumption. Based on that, this research aims to analyze the existing problems in the honey production in the state of Paraiba. As for the methodological procedures, was initially done a literature review to identify problems of honey production reported in the literature, then semi-structured interviews were conducted with specialists working in Paraiba beekeeping and listed the problems encountered in the production of honey in the state. This list has been validated by the interviewees. For the ranking of the problems we used the Analytic Hierarchy Process (AHP). The survey results show that among the steps of the production process maintenance is the step that has more impact in the process, and that the major problems existing in Paraiba beekeeping are the proximity of the apiary to livestock and horse, the lack of management of supers, lack of hygiene during honey processing process, lack of flowering calendar and the poor location of the apiary.

Keywords: Family Farming, Beekeeping, AHP.

\footnotetext{
*Autor para correspondência

Recebido para publicação em 05/03/2016; aprovado em 19/05/2016

${ }^{1}$ Mestre em Sistemas Agroindustriais - CCTA/UFCG, Campus Pombal. E-mail: rubeniaadm@gmail.com

${ }^{2}$ Graduando em Administração -CCSA/UFPB, Campus João Pessoa. E-mail: augusto.100@ hotmail.com

${ }^{3}$ Professora Doutora do Curso de Agronomia - CCTA/UFCG, Campus Pombal. E-mail: alinecfx@yahoo.com.br

${ }^{4}$ Mestre em Sistemas Agroindustriais - CCTA/UFCG, Campus Pombal, E-mail: barbara.bmp@hotmail.com

${ }^{5}$ Aluno de Graduação em Agronomia, UFCG/CCTA, Pombal-PB; E-mail: t.pimenta62@ gmail.com

${ }^{6}$ Mestrando em Sistemas Agroindustriais - CCTA/UFCG, Campus Pombal. E-mail: bdeandrade3@gmail.com
} 


\section{INTRODUÇÃO}

A produção de mel no Brasil representa uma das atividades que fornece grandes oportunidades para a agricultura familiar na região nordeste do país possibilitando um desenvolvimento econômico e social para os que exercem essa ocupação. Ela é caracterizada como agricultura familiar, porque é desenvolvida pelos pais, filhos e familiares que identificam nela uma forma de ocupação e renda. Além disso, quando se volta para o serviço de extração de mel, verifica-se que a barreira de entrada para essa ocupação é baixa.

No Brasil existem duas formas de produção de mel: uma através da meliponicultura que consiste na criação das abelhas nativas ou abelhas sem ferrão, as melíponas; a outra forma por meio da apicultura, que consiste na exploração econômica e racional da abelha do gênero Apis e espécie Apis Mellifera sendo responsável pela maior parte da produção de mel no País (BAYLE, 2013).

De acordo com Silva (2010) a apicultura condiz com o tripé da sustentabilidade: o social, o econômico e o ambiental. Economicamente ela se destaca por gerar emprego e renda, além de ser uma atividade que proporciona lucro aos agricultores. No âmbito social ela proporciona um melhor desenvolvimento do homem no campo, ajudando a fomentar o polo de desenvolvimento local. O âmbito ambiental ela age como polinizadores naturais de espécies nativas e cultivadas contribuindo para o equilíbrio do ecossistema e manutenção da biodiversidade.

$\mathrm{Na}$ apicultura extraem-se diversos produtos tais como: mel, pólen, própolis, cera e apitoxina. De acordo com Freitas (1998) outro produto produzido pela apicultura que vem se desenvolvendo é o serviço de polinização, que consiste em alugar colmeias para outros produtores a fim de aumentar a produtividade.

Freitas, Khan e Silva (2004) afirmam que o mel é considerado o produto apícola que apresenta maior facilidade de ser explorado e melhor comercializado devido a sua grande utilidade. $\mathrm{O}$ mel é utilizado nas indústrias alimentícias, farmacêuticas e cosméticas o que gera uma demanda cada vez mais crescente para os apicultores.

Segundo Oliveira (2012), os dados estatísticos do Instituto Brasileiro de Geografia e Estatística (IBGE) permite concluir que a apicultura na região nordeste vem tendo um forte crescimento desde o início da década passada, aumentando sua participação relativa na produção nacional. Esta região apresenta grande potencial produtivo, devido às condições climáticas e a vegetação nativa.

Silva (2010, apud LEVY, 1998) afirma que a região nordeste apresenta um grande potencial apícola e que o mel produzido nessa região possui uma boa qualidade devido as suas floradas apícolas que são nativas e livres de produtos químicos

Além das condições climáticas, a tecnologia, os equipamentos e as técnicas contribuem com a produtividade do mel. Vilela (2002) afirma que seguindo a tecnologia recomendada na produção e comercializando o mel de maneira adequada, tem-se uma maior rentabilidade na atividade.

De acordo com Silva (2010) a informalidade no processo produtivo, o mau uso ou a ausência da tecnologia, a falta da casa de mel e o mau gerenciamento da produção são os maiores entraves que interferem nos níveis de produtividade do mel.

Durante o processo produtivo do mel existem alguns problemas como a falta de higiene da etapa de beneficiamento, a manutenção errada dos apiários, a falta de equipamentos adequados, o manejo errado das melgueiras e a baixa profissionalização dos apicultores que acarretam em entraves e perda de produção de mel.

A maioria dos criadores inicia-se na apicultura observando os outros criadores, o que acaba gerando uma distorção no manejo apícola e nas técnicas utilizadas durante todo o processo produtivo, impactando negativamente não somente a produtividade, mas a qualidade do mel o que compromete a conquista de mercado e a rentabilidade do negócio (BELCHIOR FILHO, 2004).

Assim, baseado nas limitações existentes na cadeia produtiva do mel que compromete a qualidade do produto, geram perdas de produção e dificuldade de gestão resultando em menor lucratividade, impedindo o setor de atingir maiores níveis de mercado. Diante disso, este trabalho objetivou analisar os problemas existentes na produção de mel do Estado da Paraíba com a utilização do método de análise hierárquica (AHP).

\section{MATERIAL E MÉTODOS}

Os procedimentos iniciaram realização um levantamento bibliográfico para identificar os problemas da produção de mel apontados na literatura. Em seguida foram realizadas quatro entrevistas não estruturadas com especialistas em apicultura do Estado, para uma maior familiarização a cerca da apicultura paraibana e do processo de produção de mel do Estado.

Baseado no processo produtivo do mel, agrupou-se o processo produtivo do mel em três áreas administrativas: logística, gestão e produção. Dentro da área de produção subdividiu-se em instalação, manutenção e beneficiamento.

A área de gestão compreende as atividades necessárias para gerir o agronegócio, desde atividades no campo até as atividades financeiras, como pagamento de impostos, controle de custos, anotações de quanto é produzido, vendido e o quanto é gasto, para que diante dessas informações o apicultor saiba se está tendo lucro ou prejuízo. Além disso, a gestão proporciona um maior controle sobre o negócio.

A área de logística compreende os processos que são imprescindíveis ao provimento de recursos e materiais necessários para o desenvolvimento da atividade, envolvendo o armazenamento, transporte, distribuição e reposição desde a matéria-prima até o produto acabado no ponto de consumo.

Da área de produção fazem parte os processos de instalação, manutenção e beneficiamento, esta área é responsável pelo controle e desenvolvimento de técnicas utilizadas para organizar o processo produtivo a fim de atender a demanda.

Para mensurar o impacto de cada processo na produção de mel utilizou-se o método de análise hierárquica (AHP). Este método permite ordenar-se de forma hierárquica o problema, proporcionando uma visualização geral dos objetivos, critérios e alternativa auxiliando na avaliação da dimensão e conteúdo dos critérios.

Fez-se uma matriz de julgamento com as cinco áreas administrativas. Com a realização de entrevistas com 
especialistas na área de apicultura para que fossem avaliados os critérios pareados da matriz de julgamentos através de questionamentos com os impactos relativos que cada área no processo produtivo, com base na escala numérica de Saaty. Desta forma, os critérios foram representados por uma matriz de julgamentos $A_{5 \times 5}$, na qual foram comparados em relação à identificação de qual área tem maior impacto no processo produtivo.

Seguiu-se com os cálculos propostos pelo método AHP, calculou-se o autovetor de cada problema, o autovetor máximo ( $\lambda$ máx), IC e RC, o índice de consistência (IC) e a razão de consistência (RC) a fim de identificar se as respostas estavam consistentes.

De acordo com o método AHP para que haja consistência das avaliações pareadas é necessário que a razão de consistência seja menor que 0,1 . Após todos os cálculos o valor da razão de consistência encontrado foi menor que 0,1 e podem-se seguir os cálculos.

\section{RESULTADOS E DISCUSSÃO}

A tabela 1 apresenta o impacto de cada área no processo de produção de mel, com base no autovetor normalizado, em que em ordem decrescente tem-se: Manutenção, Beneficiamento, Gestão, Logística e Instalação.

Tabela 1. Matriz normalizada do processo produtivo de mel do estado da Paraíba.

\begin{tabular}{cc}
\hline Áreas Administrativas & Autovetor Normalizado \\
\hline Instalação & $5,03 \%$ \\
Manutenção & $41,82 \%$ \\
Beneficiamento & $25,20 \%$ \\
Gestão & $15,90 \%$ \\
Logística & $12,05 \%$ \\
\hline
\end{tabular}

Conforme se observa na Tabela 1 , o processo que obteve o maior impacto foi manutenção com um valor de 41,82\%. Este processo manutenção interfere em todos os outros processos, pois através da manutenção é possível identificar quais aspectos produtivos devem ser mantidos e/ou corrigidos, portanto através da manutenção é possível adotar medidas preventivas. Além disso, a manutenção contribui para que haja uma maior qualidade do mel. Lourezon et al, (2012) afirmam que o produtor deve garantir a inocuidade do alimento, e alcançar o status de alimento seguro, ou seja, que não contenha elementos nocivos para a saúde dos consumidores. A garantia da produção segura pode ser alcançada através da aplicação das Boas Práticas da Apicultura (BPA) as quais identificam as medidas higiênicas e sanitárias na condução de todo o processo produtivo.

$\mathrm{O}$ beneficiamento foi o a segunda área de maior com $25,20 \%$ do autovetor total, esta processo possui uma importância relevante. O beneficiamento do mel é feito na Unidade Extratora de Mel (UEM) cuja construção deve ser feita de acordo com as normas predeterminadas pelos Órgãos competentes. A manipulação de produtos alimentícios deve ser feita de forma higiênica e segura. A higiene pessoal bem como a higienização e sanitização da UEM, dos equipamentos e dos utensílios utilizados é necessária para garantir um produto com qualidade livre de contaminações por microrganismos. Todo o processo de beneficiamento é feito por meio do manuseio do homem, nessa etapa é preciso atentar-se para os cuidados de higiene e manejo correto, evitando perdas de produção (SENAR, 2010).

Com $15,90 \%$ foi o valor observado pelo do autovetor total para a Gestão. Uma administração adequada proporciona uma produção eficiente, com maior controle sobre o agronegócio e uma maior rentabilidade. O SEBRAE/PB (2006) afirma que o nível de gestão ainda é muito incipiente na apicultura da Paraíba, poucos apicultores fazem controle de caixa, cadastro de clientes e acompanham o mercado. A logística e a instalação atingiram $12,05 \%$ e 5,03\%, respectivamente sendo as áreas de menores valores. Segundo Perreira et al (2003) o sistema de produção de mel é simples e de fácil instalação, devendo ser observado a escolha do local, o pasto apícola, a facilidade de acesso e a distribuição das colmeias visto que todos esses fatores impactam diretamente na produção.

A hierarquização apresentada na Tabela 2 foi adequada, as respostas foram consistentes de acordo com o valor da razão de consistência, apresentada na Tabela 2.

Tabela 2 - Cálculo do autovetor máximo ( $\lambda$ máx), o índice de consistência (IC) e a razão de consistência (RC) para analise dos problemas existentes na produção de mel do Estado da Paraíba.

\begin{tabular}{cc}
$\lambda$ máx & 5,07065 \\
IC & 0,01766 \\
RC & 0,0158 \\
\hline
\end{tabular}

Conforme apresentado na Tabela 3, é possível perceber e mensurar o impacto de cada problema na cadeia produtiva do mel no Estado da Paraíba. O maior problema é a falta de manejo das melgueiras com (20,33\%). Segundo Pereira et al, (2003) o manejo eficiente das colmeias é um fator crucial para o sucesso da atividade, pois é durante o manejo das melgueiras que o apicultor observa a quantidade de alimento disponível, a presença e a qualidade da postura da rainha e o desenvolvimento das crias. O que fornece ao apicultor condições de tomar medidas mitigadoras preventivas.

$\mathrm{O}$ segundo maior problema são as colônias fracas $(15,20 \%)$. Este problema geralmente é consequência da falta de alimento disponível no campo, divisão natural de enxames, rainhas velhas e enxames recém-capturados. Além de não produzirem, essas colônias são alvo fácil de pragas e doenças. Para evitar esses problemas, o apicultor deve fortalecer ou unir essas colmeias (PEREIRA et al., 2003).

O terceiro problema de maior impacto é a falta de higiene durante o beneficiamento do mel $(13,73 \%)$. Durante o beneficiamento é imprescindível que se tenha cuidado com a higiene devido ao contato direto do apicultor com o mel. O SEBRAE/NA (2009) enfatiza que o contato com superfícies sujas, veículos de transporte sujos e equipamentos e máquinas de envase sujos são fontes de contaminação. A falta de higiene dos manipuladores nas diferentes etapas de produção do mel, nas casas de mel e no entreposto pode acarretar em contaminação de origem fecal dos produtos e isso torna o mel impróprio para o consumo humano.

Verifica-se que os três primeiros problemas representam um impacto de 49,26\% isso demostra a importância desses fatores na cadeia produtiva e o quanto a sua falta impacta negativamente em todo o processo de produção do mel.

O quarto problema é a falta de calendário de floradas $(8,77 \%)$ este problema apresenta-se como um grande entrave 
por ocasionar a falta de néctar floral para as abelhas, o que influencia diretamente na produtividade de mel.

A realização desse calendário é extremamente importante, pois, conforme Wolff (2008), este calendário possibilita a identificação dos períodos de máxima oferta de alimentos (néctar e pólen) às abelhas e a análise dos momentos mais adequados para o planejamento e a antecipação dos manejos nas colmeias.

Tabela 3 - Impacto dos problemas na cadeia produtiva de mel no estado da Paraíba

\begin{tabular}{|c|c|}
\hline Impacto & Contribuição \\
\hline Falta do manejo das melgueiras & $20,33 \%$ \\
\hline Colônias fracas & $15,20 \%$ \\
\hline $\begin{array}{l}\text { Falta de higiene durante o processo de } \\
\text { beneficiamento do mel }\end{array}$ & $13,73 \%$ \\
\hline Falta de calendário de floradas & $8,77 \%$ \\
\hline $\begin{array}{l}\text { Falta de assistência técnica aos } \\
\text { apicultores }\end{array}$ & $4,61 \%$ \\
\hline Mel verde & $4,10 \%$ \\
\hline Vestimentas inadequadas & $3,84 \%$ \\
\hline $\begin{array}{l}\text { Falta de cuidado das colmeias durante a } \\
\text { entressafra }\end{array}$ & $3,34 \%$ \\
\hline Má localização do apiário & $3,34 \%$ \\
\hline $\begin{array}{l}\text { Falta de alimentação artificial nas } \\
\text { colmeias durante a seca }\end{array}$ & $3,12 \%$ \\
\hline Não realizar a troca de cera & $2,96 \%$ \\
\hline $\begin{array}{l}\text { Proximidade do apiário à criação de gado } \\
\text { e cavalo }\end{array}$ & $2,49 \%$ \\
\hline $\begin{array}{l}\text { Beneficiamento do mel feito fora da } \\
\text { Unidade }\end{array}$ & $2,35 \%$ \\
\hline $\begin{array}{l}\text { Utilização de equipamentos inadequados } \\
\text { para beneficiamento do mel }\end{array}$ & $2,08 \%$ \\
\hline Pasto apícola de baixa qualidade & $1,82 \%$ \\
\hline $\begin{array}{l}\text { Falta de entrepostos a uma distância } \\
\text { acessível }\end{array}$ & $1,84 \%$ \\
\hline Má gestão do negócio & $1,55 \%$ \\
\hline
\end{tabular}

A falta de assistência técnica aos apicultores impacta em $4,61 \%$. A grande maioria dos apicultores não procura e nem fazem uso de serviços ligados à assistência técnica. Da parcela dos apicultores que procuram essa ajuda, muitos não colocam em prática o que aprendem. O SEBRAE/PB (2006) afirma que essa falta de assistência técnica contribui para o atraso tecnológico e gerencial da apicultura paraibana, além de gerar uma atuação insatisfatória das diversas agencias encarregadas de promover assistência aos produtores rurais, tanto nesta atividade quanto em outras atividades de produção.

Em seguida tem-se o mel verde, que consiste na retirada de favos da melgueira não maduros, ou seja, os favos ainda não estão operculados. Pereira et al (2003) afirma que o mel verde apresenta altos índices de umidade o que facilita a proliferação de leveduras, levando-o a fermentar e tornandose impróprio para o consumo. Por este motivo, o mel verde é considerado um problema, visto que o seu beneficiamento gera perda de produção, pois não pode ser consumido.

Em sétima posição tem-se o uso de vestimentas inadequadas $(3,84 \%)$, o seu uso tende a contaminar o produto, além de ser perigoso aos manipuladores que ficam expostos a picadas de abelhas e a acidentes de trabalho.

O oitavo problema é a falta de cuidado das colmeias durante a entressafra com (3,34\%). Souza (2007) afirma que na entressafra são necessários cuidados especiais. Devem-se guardar somente favos novos, distantes uns dos outros (quanto mais distante melhor) e em local bem iluminado e ventilado para que na época de safra as colmeias estejam preparadas para a produção.

Também em oitava posição tem-se a má localização do apiário com $(3,34 \%)$, geralmente o apicultor localiza o apiário em região próximo a criação de animais, distante de fonte de água e com pouco pasto apícola o que dificulta o trabalho das abelhas. A localização do apiário é muito importante, pois é o espaço onde estão instaladas as colmeias de abelha, ou seja, deve ser um espaço capaz de dá suporte as abelhas para que estas produzam mel, deve estar próximo ao pasto apícola.

A falta de alimentação artificial nas colmeias durante a seca obteve impacto de $3,12 \%$, esse problema ocasiona morte das abelhas e enfraquecimento das colmeias fracas, Pereira et al. (2003) afirma que as abelhas necessitam de reservas de alimento suficientes para atender a sua própria alimentação e das crias em desenvolvimento. Em épocas de escassez de néctar e pólen, é comum os apicultores perderem seus enxames que, enfraquecidos em razão da fome, migram à procura de condições melhores.

Em seguida, com 2,96\% está a não realização de troca de cera. Essa troca é necessária pelo fato de que as células dos quadros de ninhos que recebem a postura da rainha são gradualmente obstruídas pelos dejetos das larvas. Outro efeito do acúmulo de sujeira é a reação defensiva das abelhas que se manifesta na propensão a gerar novos enxames (SEBRAE/PB, 2006)

A proximidade do apiário à criação de gado e cavalo apresenta um impacto de 2,49\%. Isso se dá devido à falta de higienização nos currais tornando assim um ambiente impróprio para entrada de abelhas bem como pelo fato dos animais buscarem como fonte de alimentação as plantas nativas utilizadas próximo ao pasto apícola, comprometendo assim a produção de mel. Além disso, de acordo com o coordenador do Fórum de Apicultura e Meliponicultura da Paraíba a apicultura paraibana é em sua maioria uma atividade secundária, ou seja, atrelada a ela o apicultor tem uma atividade principal, que muitas vezes consiste na criação de gado e cavalo.

$\mathrm{O}$ beneficiamento do mel feito fora da Unidade apresentou um impacto de $19,54 \%$. Os procedimentos para a produção, que não são realizados as técnicas de higienização corretas dos equipamentos geram produtos de baixa qualidade ou até impróprio para o consumo.

Com impacto de $2,08 \%$ tem-se a utilização de equipamentos inadequados para beneficiamento do mel. O SEBRAE/PB (2006) relata que o uso de equipamentos e ferramentas específicos da apicultura tem seu emprego necessário e importante para a boa condução dos processos e operações que lhe são peculiares.

Em seguida vem o pasto apícola de baixa qualidade com $1,82 \%$ sendo um fator de grande importância na apicultura, pois representa o principal alimento das abelhas. Couto e 
Couto (2006) destaca que a qualidade e quantidade de seu pasto apícola são os principais fatores que limitam a produção num dado local.

A falta de entrepostos a uma distância acessível com demostrou impacto de $1,84 \%$. Em algumas cidades do interior da Paraíba o entreposto é distante da propriedade apícola o que faz com que, muitas vezes todo o processo produtivo seja feito na unidade de beneficiamento, devido à distância, pois na visão do apicultor isso acarreta em perda de dinheiro e tempo em virtude da necessidade de deslocamento.

O último problema com um impacto de 1,55\% é a má gestão do negócio. Os apicultores, em sua maioria, não fazem planejamento do negócio, controle de produção e controle financeiro. Eles não anotam dados de produção, nem informações gerenciais para que se tenham um maior controle sobre a atividade. O SEBRAE/PB (2006) afirma que o nível de gestão na apicultura paraibana é muito incipiente, tendo um baixo controle de caixa, pois não há controle de custos, cadastro de clientes e acompanhamento de mercado, o que reflete em uma má gestão de negócios.

\section{CONCLUSÕES}

O processo produtivo de maior impacto na produção de mel é o de manutenção. Os problemas que causam maior impacto na produção de mel são: falta do manejo das melgueiras, colônias fracas e falta de higiene durante o processo de beneficiamento do mel. Estes problemas são extremamente críticos, por serem problemas que estão no início da cadeia, estes comprometem todo o processo restante, além de comprometer a qualidade do mel, tornando-o impróprio para o consumo humano, gerando uma grande perda de produção.

\section{REFERÊNCIAS BIBLIOGRÁFICAS}

BELCHIOR FILHO, Valdemar. A apicultura no Rio Grande do Norte e a importância da apimondia. 2004. Disponível em: http:// www.apacame.org.br/mensagemdoce/74/artigo3.htm 2004. Acesso em setembro de 2014.

BAYLE, E. Estudo da Cadeia Produtiva do Mel no Estado do Pará/ Emmanuel Bayle. Programa de Redução da Pobreza e Gestão dos Recursos Naturais do Pará - PARARURAL, 2013.

COUTO, R. H. N; COUTO, L. Apicultura: manejo e produtos. 3 ed. aboticl: FUNEP, 2006. 191p.

FREITAS, B.M. O uso de programas racionais de polinização em áreas agrícolas. Mensagem doce. N.46, p.16-20, São Paulo: APACAME, 1998.

FREITAS, D. G. F.; KHAN, A. S. e SILVA, L. M. R. Nível tecnológico e rentabilidade de produção de mel de abelha (Apis mellifera) no Ceará. Rev. Econ. Sociol. Rural vol.42 no.1 Brasília Jan./Mar. 2004

LOUREZON, M. C. A.; TASSINARI, W. S., KOSHIYAMA, A. S., ALMEIDA, C. T. de. Indicadores \& Desafios da Apicultura Fluminense: um retrato Brasileiro. Vila Velha: Above Publicações, 2012. 272 p. il. color. ISBN: 978-8563080-83-x.
OLIVEIRA, Hamilton Reis de - Evolução da Pecuária na Região Nordeste 2000 a 2010. CIEST - Central de Informações Econômicas, Sociais e Tecnológicas ETENE Escritório Técnico de Estudos Econômicos do Nordeste. BNB Fortaleza, Novembro de 2012 166p.

PEREIRA, F. de M. et al. Produção de mel. Embrapa MeioNorte, 2003.

SEBRAE/NA - Manual de Segurança e Qualidade para Apicultura. PAS Indústria. Brasília, DF: SEBRAE/NA, 2009.86p.

SEBRAE/PB - Apicultura paraibana. Serviço Brasileiro de Apoio às Micros e Pequenas Empresas da Paraíba. João Pessoa: SEBRAE/PB, 2006. 69 p.; il.

SENAR, 2010. Mel: manejo de apiário para produção do mel / Serviço Nacional de Aprendi- zagem Rural. -- 2. ed. Brasília. SENAR, 2010.

SILVA, EDINILSON AUGUSTO da. Apicultura sustentável: produção e comercialização de mel no sertão sergipano / Edinilson Augusto da Silva. - São Cristóvão, 2010. xix, 153 f. : il. Dissertação (Mestrado em Desenvolvimento e Meio Ambiente) - Núcleo de Pós-Graduação em Desenvolvimento e Meio Ambiente, Universidade Federal de Sergipe, 2010.

SOUZA, Darcet Costa - Org. Apicultura: manual do agente de desenvolvimento rural/ Organizado por Darcet Costa Souza._2. ed. rev._Brasília: Sebrae, 2007. 186 p.; il. 2007.

VILELA, Sérgio Luiz de Oliveira; PEREIRA, Fábia de Melo. Cadeia produtiva do mel no Estado do RN. Natal: SEBRAE/RN, 2002. 130p.

WOLFF, L. F. et. al., Flora apícola arbórea nativa na reião serrana de Pelotas para a apicultura sustentável do Rio Grande do Sul/Luís Fernando Wolff... [et. al.] - Pelotas: Embrapa Clima Temperado 2008. 37 p. - (Embrapa Clima Temperado. Documentos, 242). 